\title{
Padrão de Distribuição de Células Mononucleares de Medula Óssea em Tecido Cardíaco Sadio por Diferentes Vias de Infusão
}

\author{
Vívian Yochiko Samoto ${ }^{1,2}$, Erika Renata Branco ${ }^{3}$, Guilherme José Bolzanio de Campos Ferreira ${ }^{3}$, \\ Rosa Maria Cabral ${ }^{3}$, Guilheme Buzon Gregores ${ }^{3}$, André Luiz Silveira Sousa ${ }^{4}$, \\ Hans Fernando Rocha Dohman ${ }^{4}$, Suzana Alves Silva ${ }^{4}$, Christina Maeda Takiya ${ }^{1}$, \\ Maria Isabel Doria Rossi ${ }^{1}$, Radovan Borojevic ${ }^{1}$, Maria Angélica Miglino ${ }^{3}$
}

\section{RESUMO}

Introdução: A medicina regenerativa tem ganho grande importância nos últimos anos em decorrência da possibilidade de certas células se diferenciarem em linhagens celulares distintas e, assim, reconstruírem o tecido lesado. As células-tronco têm despontado como forma alternativa de tratamento para doenças pela sua capacidade de diferenciação nos mais de 100 tipos de tecido. A medula óssea contém células-tronco adultas, hematopoéticas e mesenquimais, que auxiliam na limitação do remodelamento cardíaco. Método: Foram utilizados 9 cães com peso entre $25 \mathrm{~kg}$ e $30 \mathrm{~kg}$, divididos em três grupos: intracoronária, intramiocárdica-transendocárdica e retrógrada venosa. Células mononucleares da medula óssea foram coletadas por densidade Ficoll, marcadas com fluorocromo Hoechst e infundidas nas diferentes vias citadas anteriormente. Resultados: Observou-se que, na via intracoronária, a distribuição das células foi homogênea do epicárdio ao endocárdio, em átrios e ventrículos direito e esquerdo; na via intramiocárdica-transendocárdica, as células ficaram mais restritas ao local da infusão, com consequente maior número em ventrículo esquerdo; e na via retrógrada venosa, as células encontravam-se com padrão de distribuição semelhante ao da via intramiocárdica, contudo sem que as mesmas chegassem à região endocárdica. Com relação à quantidade de células distribuídas pelo tecido, foi observado que havia diferença significativa $(P<0,01)$, quando analisada a interação via de infusão vs. região. Conclusão: Podemos concluir que existe a possibilidade

\author{
ABSTRACT \\ Interaction Between Infusion Route and Bone \\ Marrow Mononuclear Cell Distribution Patterns \\ in Normal Cardiac Tissue
}

Background: Regenerative medicine has become increasingly important in recent years due to the possibility of certain cells to differentiate into different cell lines and thus recover the damaged tissue. The stem cell has emerged as an alternative treatment for diseases as a result of their ability to differentiate in more than 100 types of tissue. Bone marrow contains adult stem cells, hematopoietic and mesenchymal cells, which limit heart remodeling. Methods: Nine dogs weighing between 25 and $30 \mathrm{~kg}$ were divided into three groups: intracoronary group, intramyocardial-transendocardial group and retrograde venous group. Mononuclear cells were collected from bone marrow by Ficoll density, stained with Hoechst fluorocrom and infused through the different routes mentioned above. Results: It was observed that distribution of the cells was homogeneous from the epicardium to the endocardium in the right and left atrium and ventricle when the intracoronary route was used. With the transendocardial route the cells were more restricted to the infusion site, with a consequent larger number in the left ventricle. A similar distribution pattern was observed with retrograde venous infusion, however, cells did not reach the endocardial region. As to the number of cells distributed over the tissue, a significant difference $(P<0.01)$ was observed for the interaction

\footnotetext{
1 Universidade Federal do Rio de Janeiro - Rio de Janeiro, RJ, Brasil.

2 Universidade Federal de São Paulo - São Paulo, SP, Brasil.

3 Universidade de São Paulo - São Paulo, SP, Brasil.

4 Hospital Pró-Cardíaco PROCEP - Rio de Janeiro, RJ, Brasil.

Correspondência: Vívian Yochiko Samoto. Rua Barata Ribeiro, 160/

809 - Copacabana - Rio de Janeiro, RJ, Brasil - CEP 22011-002

E-mail: vysamoto@gmail.com

Recebido em: 7/1/2009 • Aceito em: 3/6/2009
} 
Samoto VY, et al. Padrão de Distribuição de Células Mononucleares de Medula Óssea em Tecido Cardíaco Sadio por Diferentes Vias de Infusão. Rev Bras Cardiol Invas. 2009;17(2):220-6.

de empregar técnicas distintas de entrega de células para diferentes doenças cardíacas.

DESCRITORES: Células-tronco. Transplante de célulastronco. Transplante de células/métodos. Cães. between the infusion route versus region. Conclusion: We concluded that different cell delivery techniques may be used according to the different heart diseases.

DESCRIPTORS: Stem cells. Stem cell transplantation. Cell transplantation/methods. Dogs.
A despeito dos grandes avanços na terapia farmacológica e no tratamento cirúrgico, o infarto do miocárdio ainda é uma doença com alta prevalência na população mundial e os países em desenvolvimento têm demonstrado as mesmas características epidêmicas ${ }^{1}$. A maior causa de falência cardíaca resulta da oclusão das artérias, sendo a perda de fluxo sanguíneo responsável pelas alterações do funcionamento do miocárdio. Entende-se por remodelamento cardíaco variações moleculares, celulares e intersticiais cardíacas, que vão se manifestar clinicamente por alterações no tamanho, na massa, na geometria e na função do coração ${ }^{2}$. Por isso, estudos clínicos e experimentais têm enfocado a limitação do tamanho do infarto ${ }^{3}$.

As células-tronco têm por característica a habilidade de se proliferar continuamente, de se autorrenovar e de se diferenciar em vários tecidos, emergindo como forma alternativa para o tratamento de várias doenças ${ }^{4,5}$. A maioria dos estudos para o tratamento do infarto do miocárdio emprega a utilização de células adultas, como o mioblasto esquelético ${ }^{6,7}$, de células mesenquimais ${ }^{8-10}$, e de células mononucleares da medula óssea, obtidas por meio de punção da medula óssea ${ }^{11}$.

Além do emprego de novas formas de tratamento, buscam-se também meios menos invasivos de sua implantação em tecido cardíaco. O cateterismo cardíaco é um procedimento de rotina, não-cirúrgico, utilizado como forma tanto diagnóstica como de tratamento (angioplastia). A técnica de infusão de células pela via arterial intracoronária é segura e não possui evidências de aumento de taxas de reestenose, encontrando-se as células dispersas em todas as camadas musculares ${ }^{12}$. A via intramiocárdica de entrega de células em tecido cardíaco pode ser utilizada nos casos em que o emprego da via intracoronária é inadequado; no entanto, em decorrência de sua habilidade de entregar as células de modo seletivo nas regiões normais e peri-infartadas, eventos como extrassístoles e arritmia ventricular podem ser observados ${ }^{13}$. Recentemente, foi aventado o emprego da via retrógrada venosa como uma possível via de entrega de células ${ }^{14}$. Este trabalho tem por objetivo avaliar a interação via de infusão vs. padrão de distribuição de células, o que pode direcionar o profissional na escolha de qual metodologia de entrega de células seria mais eficaz de acordo com a doença cardíaca apresentada pelo paciente.

\section{MÉTODO}

O projeto de pesquisa foi aprovado pelo Comitê de Bioética da Faculdade de Medicina Veterinária e Zootecnia da Universidade de São Paulo, protocolo número 640/2005, sendo permitida a utilização de 9 cães com peso aproximado de $25 \mathrm{~kg}$ (3 animais por grupo). Para a inclusão dos animais foram realizados exames bioquímicos séricos para alanina aminotransferase, creatina quinase fração $M B(C K-M B)$, creatinina, hemograma, eletrocardiografia e ecocardiografia. Somente os animais que apresentavam resultados dentro dos parâmetros normais foram incluídos no estudo.

\section{Obtenção das células mononucleares da medula óssea}

As células mononucleares da medula óssea foram obtidas por meio de punção da crista ilíaca com aguIha para punção de medula óssea em seringa heparinizada, separadas por gradiente de densidade FicollPaque PLUS ${ }^{\mathrm{TM}}$ (Amersham Biosciences, Freiburg, Alemanha) e marcadas com fluorocromo Hoechst 33258 (Sigma-Aldrisch, St Louis, Estados Unidos), e a viabilidade celular foi analisada pelo método de coloração com azul tripano (trypan blue). Para as vias intracoronária e retrógrada venosa, 100 milhões de células foram ressuspensas em $10 \mathrm{ml}$ de solução fisiológica, enquanto na via transendocárdica a mesma quantidade de células foi ressuspensa em $3 \mathrm{ml}$ de solução fisiológica.

\section{Vias de infusão para entrega celular em tecido cardíaco}

Este estudo teve como objetivo avaliar qual via de entrega de células em tecido cardíaco levava a maior enxertia dessas células e qual o padrão de sua distribuição mediante as diferentes propostas de infusão. Para isso, focamos a entrega celular em ventrículo esquerdo, principalmente na parede ântero-lateral. Como a vascularização do ventrículo esquerdo é feita principalmente pelo ramo interventricular anterior, escoIhemos realizar a infusão das células nesse ramo.

A via intracoronária anterógrada é uma via de acesso frequentemente utilizada como via de diagnós- 

por Diferentes Vias de Infusão. Rev Bras Cardiol Invas. 2009;17(2):220-6.

tico. Por ser uma via de rápido acesso e baixo risco, aventou-se a possibilidade de sua utilização como via de entrega de células. Neste estudo, seguiu-se a metodologia descrita por Suzuki et al. ${ }^{15}$ e Strauer et al. ${ }^{16}$. Com auxílio de fluoroscopia (fluoroscópio OEC PLUS 2400 - GE OEC Medical Systems Inc., Salt Lake City, Estados Unidos), o cateter foi posicionado no ramo intermédio da artéria circunflexa esquerda (artéria descendente anterior em humanos) e foram realizadas infusões em bolo de $2 \mathrm{ml}$ a $3 \mathrm{ml}$, com intervalos de cerca de três minutos.

A via retrógrada venosa inicialmente foi utilizada para infusão de solução para cardioplegia e como via de administração de medicamentos ${ }^{10}$; recentemente, com a proposta da terapia celular como forma terapêutica, sugeriu-se a via retrógrada venosa como alternativa para a implantação em tecido cardíaco. Em nosso estudo, utilizamos a técnica descrita por Rangappa et al. ${ }^{17}$ e Suzuki et al. ${ }^{18}$ e reproduzida por Yokoyama et al. ${ }^{19}$, na qual o cateter transpassa o seio coronário até a veia interventricular anterior, sendo posicionado na mesma região em que foi realizada a infusão coronária arterial. Isso é possível pela disposição das veias, paralelas às artérias na superfície do coração.

Para a infusão intramiocárdica, seguiu-se a técnica descrita por Kornowski et al. ${ }^{20}$ e Perin et al. ${ }^{21}$, e o volume e as concentrações celulares foram baseados em estudo de Fuchs et al. ${ }^{22}$, no qual 108 células estavam diluídas em volume de $3 \mathrm{ml}$ e foram injetadas no músculo cardíaco com uma média de 12 injeções, tendo sido escolhida a parede ântero-lateral como a região para realização das injeções. Para essa técnica de infusão, além do equipamento básico, fluoroscópio, foi necessária a utilização de equipamento para realização de mapeamento cardíaco e de cateter NOGA $^{\mathrm{TM}}$ (Biosense-Webster, Haifa, Israel). Todo o procedimento de coleta e infusão de células era realizado com o animal em plano anestésico, com a utilização do seguinte protocolo: medicação pré-anestésica e indução (propofol $2 \mathrm{mg} / \mathrm{kg}$ - Cristália, São Paulo, Brasil) e manutenção (isofluorano - Cristália, São Paulo, Brasil). Uma hora após a infusão, os animais eram submetidos a eutanásia com infusão intravenosa contínua de cloreto de potássio, sendo o coração coletado e fracionado em regiões (átrio, basal, medial e apical), para que fossem realizadas análises por microscopia de luz com coloração de hematoxilina-eosina, com fixação por formaldeído $10 \%$ em tampão fosfato.

Para a análise quantitativa de células Hoechst positivas, utilizou-se a microscopia de epifluorescência, com fixação das lâminas em acetona PA e contracoradas com azul de Evans. As regiões de escolha para análise foram o ventrículo e o átrio esquerdos, fracionados em regiões basal, média e apical; contudo, átrio e ventrículo direitos também foram analisados, mas não quantificados. Aproximadamente 100 lâminas, referência e look-up, foram analisadas e os resultados foram avaliados por meio do teste PROC MIXED, do programa Statistical Analysis System, versão 8.0 (SAS Institute, Cary, Estados Unidos), no qual se considerou a mensuração de cada animal como medida repetida.

Foram considerados os efeitos principais de via de infusão, as regiões de avaliação, bem como a interação entre os efeitos principais via vs. região. Nessas análises, foi adotado o seguinte modelo estatístico:

$$
y i j k=\mu+V i+R j+V R i j+e i j k
$$

em que yijk = número de células marcadas no animal $k$, na região $j$, e que recebeu a via de infusão $i ; \mu=$ constante inerente a todas as observações; $\mathrm{Vi}=$ efeito da i-ésima via de infusão, sendo i = 1 (intracoronária), 2 (transendocárdica) e 3 (retrógrada); $\mathrm{Rj}=$ efeito da j-ésima região de avaliação, sendo $\mathrm{j}=1$ (atrial), 2 (basal), 3 (medial) e 4 (apical); VRij = efeito da interação da via i com a região j; e eijk = efeito aleatório residual associado ao número de células marcadas no animal k, na região j, e que recebeu a via de infusão i.

Para análise de comparação múltipla, ou seja, comparação entre as vias, o método estatístico escoIhido foi o de Bonferroni e somente os valores com $\mathrm{P}<0,05$ foram considerados significativos. Utilizamos para a realização da análise o programa Prisma Graph, versão 5.0 (GraphPad Software, San Diego, Estados Unidos).

\section{RESULTADOS}

\section{Separação e viabilidade celular}

Procedimentos de coleta, separação e marcação celular com fluorocromo foram realizados. A quantidade de 108 células pôde ser obtida de cada animal e a viabilidade celular foi de aproximadamente $98 \%$.

\section{Padrão de distribuição}

Não houve intercorrências graves durante o procedimento de infusão celular e não foram observadas alterações macroscópicas por ocasião da coleta do coração para análise histopatológica.

Na via intracoronária, pudemos observar, por meio da coloração de hematoxilina-eosina, que havia grande concentração de células mononucleares distribuídas em todas as câmaras cardíacas, inclusive em septo. As células encontravam-se distribuídas entre as fibras musculares e em regiões próximas às artérias. Menor concentração de células pôde ser observada em região epicárdica e endocárdica, sugerindo, assim, um padrão intersticial de distribuição das células (Figuras 1A, 1A1 e 1A2).

Na via intramiocárdica-transendocárdica, o padrão de distribuição celular restringiu-se principalmente ao local onde foram realizadas as injeções das células no coração, 
Samoto VY, et al. Padrão de Distribuição de Células Mononucleares de Medula Óssea em Tecido Cardíaco Sadio por Diferentes Vias de Infusão. Rev Bras Cardiol Invas. 2009;17(2):220-6.
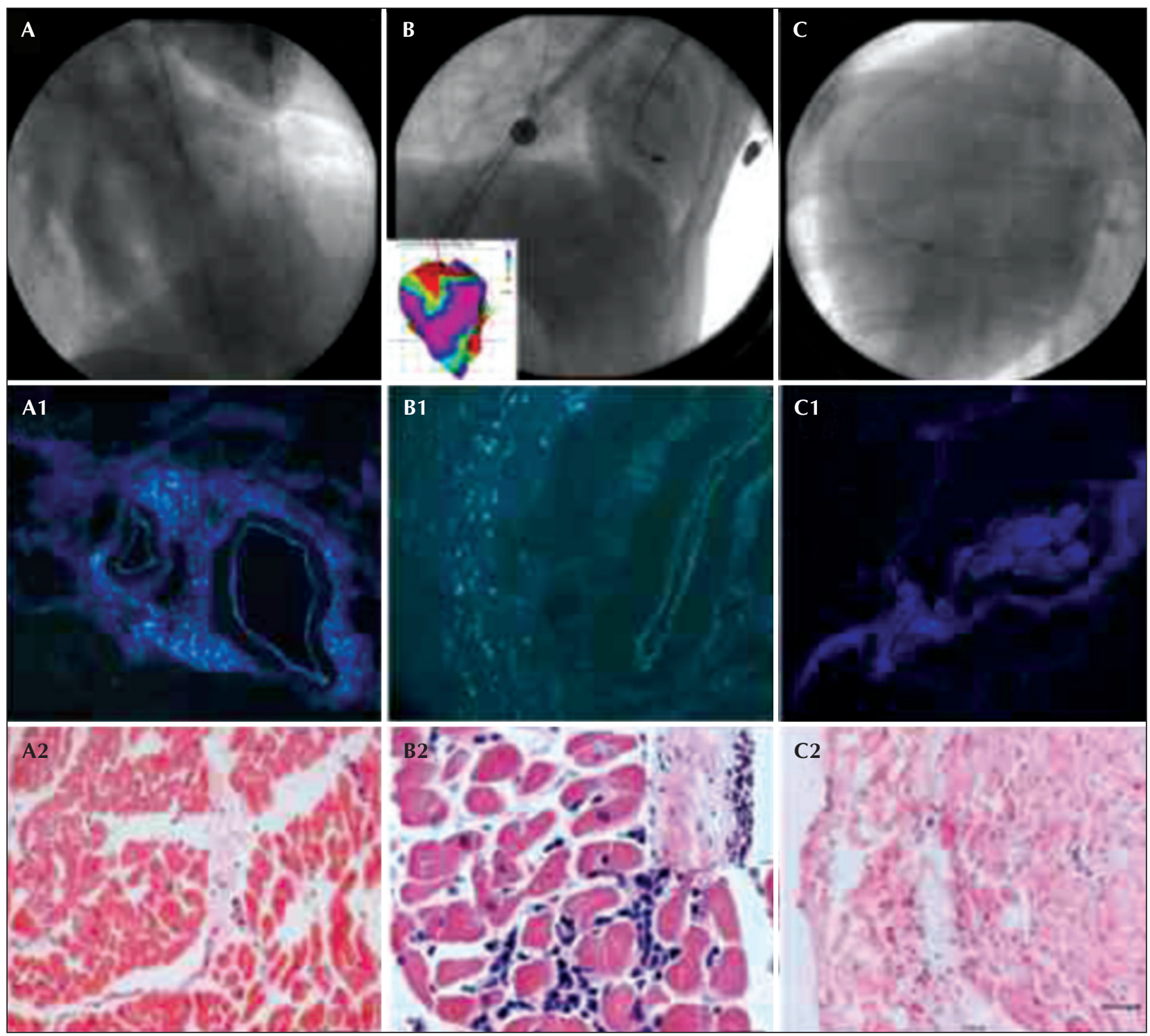

Figura 1 - A, A1 e A2 = imagens referentes à via intracoronária. $\mathrm{A}=$ localização do cateter no ramo interventricular; $\mathrm{A} 1=$ marcação de células mononucleares em região perivascular; $\mathrm{A} 2=$ distribuição de células mononucleares em interstício muscular. B, B1 e B2 = imagens referentes à via intramiocárdica-transendocárdica. B = localização do cateter Noga na região ântero-posterior, bem como os pontos de infusão; B1 = distribuição de células DAPI-positivas em região perivascular; B2 = notar a formação de cluster celular no local da infusão. C, C1 e C2 = imagens referentes à via de infusão retrógrada venosa. $\mathrm{C}=$ posicionamento dos cateteres arterial e venoso na mesma região de infusão utilizada pela via intracoronária; $\mathrm{C} 1$ = distribuição de células em região perivascular; $\mathrm{C} 2$ = distribuição instersticial de células, que, no entanto, se encontravam mais restritas à região epicárdica.

ou seja, na parede ântero-lateral. Contudo, algumas células foram observadas em septo cardíaco, átrios direito e esquerdo e em ventrículo direito. Havia predominância de células em tecido conjuntivo, principalmente no epicárdio e no endocárdio (Figuras 1B, 1B1 e 1B2).

Pela via retrógrada, foi observada distribuição celular semelhante à das vias anteriormente citadas, com grande quantidade de células mononucleares entre as fibras musculares e em tecido conjuntivo, principalmente em epicárdio; contudo, diferentemente da via intramiocárdica-transendocárdica, poucas células fo- ram encontradas em região de endocárdio (Figuras 1C, 1C1 e 1C2).

Essa disposição celular foi confirmada pela análise de microscopia de fluorescência, uma vez que as células foram previamente coradas com marcador nuclear para que posteriormente pudéssemos rastrear as células.

\section{Análise quantitativa}

Na análise estatística, verificou-se que a interação via vs. região apresentou resultados altamente signifi- 
Samoto VY, et al. Padrão de Distribuição de Células Mononucleares de Medula Óssea em Tecido Cardíaco Sadio por Diferentes Vias de Infusão. Rev Bras Cardiol Invas. 2009;17(2):220-6.

cativos $(P<0,01)$, indicando a dependência das vias de infusão diante das diferentes regiões avaliadas. O número médio de células marcadas segundo as regiões, dentro de cada via de infusão, encontra-se na Tabela 1 e na Figura 2.

Verificando-se o comportamento das regiões dentro de cada via de infusão avaliada (nas linhas), observa-se que, dentro da intracoronária, o número de células marcadas no átrio diferiu estatisticamente $(P<0,01)$ em relação às regiões medial e apical. Entretanto, para essa via de infusão, as menores quantidades de células marcadas foram observadas nas regiões medial e basal. Para a via de infusão transendocárdica, as regiões atrial e apical não apresentaram diferenças significativas entre si e foram as de maiores números de células marcadas. Menores quantidades de células marcadas, para a região transendocárdica, foram verificadas para as regiões basal e medial. Para a via de infusão retrógrada, maior quantidade de células marcadas foi observada para as regiões atrial e medial. Entretanto, as regiões atrial, basal e apical não apresentaram diferenças significativas entre si $(P>0,05)$. O comportamento das regiões avaliadas, segundo as vias de infusão, pode ser verificado na Tabela 2 .

Quando realizada comparação entre as vias, ou seja, quando avaliado o número total de células enxertadas nos diferentes protocolos de infusão, observamos que há diferença significativa entre as vias intracoronária vs. retrógrada e transendocárdica vs. retrógrada, com $\mathrm{P}<0,01$ (Figura 3).

\section{DISCUSSÃO}

A introdução das células-tronco como forma terapêutica para o tratamento de doenças isquêmicas é recente, e antes de sua utilização como forma de tratamento devemos avaliar os riscos de seu emprego. Neste estudo, utilizamos o transplante autólogo de células. Com esse procedimento, diminuímos os riscos de rejeição e os problemas éticos ainda existentes com a utilização das células-tronco embrionárias ${ }^{13}$. Como ainda são necessários estudos de base antes da implantação dessas células-tronco em tecido cardíaco, direcionamos nossa atenção para o estudo da implantação de células em tecido cardíaco normal.

Pela via intracoronária, observamos que as células encontram-se distribuídas em todas as câmaras cardíacas, entremeadas nas fibras musculares, o que facilitaria o processo de diferenciação celular, uma vez que uma das condições para a transdiferenciação celular é o contato célula-célula e o microambiente. $\mathrm{O}$ padrão de distribuição homogêneo, de epicárdio a endocárdio, em todas as câmaras cardíacas foi descrito inicialmente por Strauer e Kornowski ${ }^{13}$ e Suzuki et al. ${ }^{15}$, exceto pela formação de nichos celulares. Isso pode ser explicado, uma vez que os animais utilizados eram sadios, não havendo, dessa forma, a liberação de citocinas, que promovem o recrutamento das células $^{23}$. Sugere-se que essa distribuição está relacionada com a própria vascularização do coração e nenhum sinal de microinfarto foi observado, resultado que difere do observado por Vulliet et al. ${ }^{24}$.

A via intramiocárdica-transendocárdica leva a uma entrega seletiva de células, uma vez que as células são infundidas diretamente no tecido cardíaco ${ }^{13}$. Também foi observada a formação de pequenos grupamentos de células. Por um lado, uma maior quantidade de células em tecido cardíaco é benéfica, pois haveria provavelmente maior formação de vasos e cardiomió-

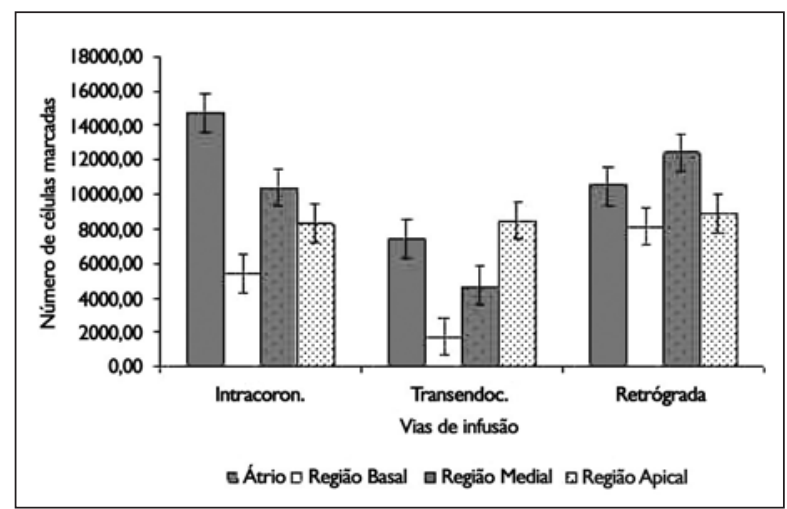

Figura 2 - Número médio de células marcadas segundo as regiões, dentro de cada via de infusão. Intracoron. = intracoronária; Transendoc. $=$ transendocárdica .

TABELA 1

Médias de quadrados mínimos do comportamento das regiões dentro de cada via de infusão

\begin{tabular}{lcccc}
\hline Via de infusão & \multicolumn{3}{c}{ Região } \\
\cline { 2 - 5 } & \multicolumn{1}{c}{ Átrio } & Região basal & Região medial & Região apical \\
\hline Intracoronária & $14.739,00^{\mathrm{a}}$ & $5.417,33^{\mathrm{c}}$ & $10.363,00^{\mathrm{b}}$ & $8.306,67^{\mathrm{b}, \mathrm{c}}$ \\
Transendocárdica & $7.426,67^{\mathrm{a}, \mathrm{b}}$ & $1.736,67^{\mathrm{c}}$ & $4.653,33^{\mathrm{b}, \mathrm{c}}$ & $8.486,00^{\mathrm{a}}$ \\
Retrógrada & $10.507,00^{\mathrm{a}, \mathrm{b}}$ & $8.132,67^{\mathrm{b}}$ & $12.439,00^{\mathrm{a}}$ & $8.894,67^{\mathrm{b}}$ \\
\hline
\end{tabular}

Médias em uma mesma linha, seguidas por uma mesma letra, não diferem entre si pelo teste PROC MIXED. 
Samoto VY, et al. Padrão de Distribuição de Células Mononucleares de Medula Óssea em Tecido Cardíaco Sadio por Diferentes Vias de Infusão. Rev Bras Cardiol Invas. 2009;17(2):220-6.

TABELA 2

Médias de quadrados mínimos para as regiões dentro de cada via de infusão

\begin{tabular}{lccrr}
\hline Via de infusão & \multicolumn{3}{c}{ Região } \\
\cline { 2 - 5 } & \multicolumn{1}{c}{ Átrio } & Região basal & Região medial & Região apical \\
\hline Intracoronária & $14.739,00^{\mathrm{a}}$ & $5.417,33^{\mathrm{a}}$ & $10.363,00^{\mathrm{a}}$ & $8.306,67^{\mathrm{a}}$ \\
Transendocárdica & $7.426,67^{\mathrm{b}}$ & $1.736,67^{\mathrm{b}}$ & $4.653,33^{\mathrm{b}}$ & $8.486,00^{\mathrm{a}}$ \\
Retrógrada & $10.507,00^{\mathrm{b}}$ & $8.132,67^{\mathrm{a}}$ & $12.439,00^{\mathrm{a}}$ & $8.894,67^{\mathrm{a}}$ \\
\hline
\end{tabular}

Médias em uma mesma coluna, seguidas por uma mesma letra, não diferem entre si pelo teste de PROC MIXED.

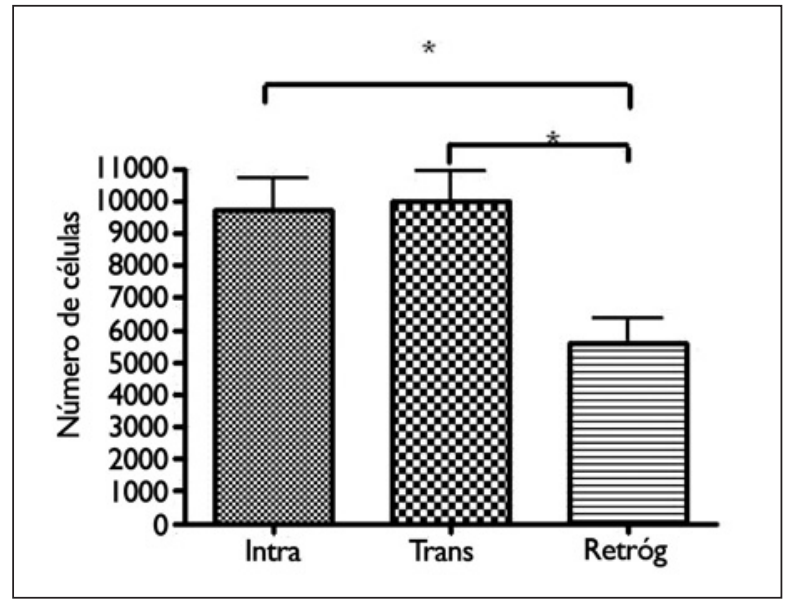

Figura 3 - Análise comparativa do número de células aderidas em tecido cardíaco pelas diferentes vias de infusão. Foi verificado, por meio da quantificação de células Hoechst positivas por metodologia estereológica, que existe diferença significativa entre as vias intracoronária vs. retrógrada e transendocárdica vs. retrógrada $(P<0,01)$. ${ }^{*} P<0,01$. Intra = intracoronária; Retróg $=$ retrógrada; Trans $=$ transendocárdica.

citos; por outro lado, um acúmulo de células pode interferir na sua diferenciação, uma vez que a diferenciação celular é influenciada pelo microambiente, pelas citocinas e pela interação célula nativa e célula transplantada. A importância da infusão de células por essa via está correlacionada com os infartos denominados intramurais e os subepicárdicos, pois, como observado, há maior quantidade de células em tecidos epicárdico e endocárdico e os nichos de células em interstício celular podem favorecer o restabelecimento do tecido lesionado. Há restrições para a realização de infusão por essa via, pois a penetração da agulha no músculo cardíaco interfere na condução do estímulo cardíaco, ou seja, este fica hiperestimulado, o que pode resultar em extrassístoles ou, em casos mais graves, fibrilação ${ }^{22}$.

A via retrógrada por seio venoso promove relativa aderência de células mononucleares em tecido cardíaCo, o que pode resultar da interferência na passagem das células pela parede das veias e também do efeito de primeira passagem em circulação pulmonar, sendo a via venosa a de eleição para infusão nesse órgão ${ }^{13}$.
A presença das células foi observada na parede do ventrículo esquerdo, assim como no ventrículo direito e no septo cardíaco. Strauer e Kornowski ${ }^{13}$ também relatam a presença de células no espaço extracelular, no chamado interstício celular, como observado em nosso estudo. A dificuldade de passagem das células para o espaço celular pode influenciar a distribuição das células no tecido cardíaco, o que explicaria a maior presença dessas células em região epicárdica, considerando-se que o calibre dos vasos nessa região também pode interferir nesse processo. A utilização de medicamentos que promovam aumento da permeabilidade vascular poderia aumentar o número dessas células no tecido. Contudo, devemos salientar que, em casos de doença coronária, essa via tem grande importância como uma via alternativa para infusão de células, diminuindo a área de lesão.

Uma característica comum entre as três vias por nós estudadas foi a grande perda de células marcadas para outros órgãos, principalmente pulmões, pelo efeito de primeira passagem, e em órgãos relacionados com a hematopoese e a linfopoese, como fígado e baço (dados não publicados), característica que também foi relatada por $\mathrm{Hou}$ et al. ${ }^{25}$. Esses autores realizaram experimentos com animais infartados, nos quais foram injetadas células radiomarcadas, fazendo, posteriormente, o rastreamento dessas células, inclusive em outros órgãos.

Concluímos que existe alta correlação entre a via de infusão e a região de enxertia celular $(P<0,01)$, podendo direcionar a escolha da técnica de entrega celular diante de diferentes doenças cardíacas. As vias que levam a maior aderência celular são a intracoronária e a transendocárdica, sem diferença significativa $(P>0,05)$. Sugerimos a utilização da via retrógrada venosa como via complementar às outras vias anteriormente citadas, pela característica de distribuição das células em ventrículo esquerdo.

\section{AGRADECIMENTOS}

Agradecemos à Fundação de Amparo à Pesquisa do Estado de São Paulo (FAPESP) e ao Centro de Ensino e Pesquisas do Pró-Cardíaco (PROCEP), pelo 
Samoto VY, et al. Padrão de Distribuição de Células Mononucleares de Medula Óssea em Tecido Cardíaco Sadio por Diferentes Vias de Infusão. Rev Bras Cardiol Invas. 2009;17(2):220-6.

financiamento e pela oportunidade oferecida de um projeto de pesquisa que subsidia pesquisa básica em terapia celular, que futuramente poderá ser empregada como forma terapêutica. Agradecemos também aos professores José Roberto Kfoury Jr., Antônio A. C. M. Ribeiro e Francisco H. Blasquez, da Faculdade de Medicina Veterinária e Zootecnia da Universidade de São Paulo, pelo empréstimo dos laboratórios LTIAM, LSCA e Laboratório de Histologia; à profa. Maria $\mathrm{H}$. A. Larsson, por nos auxiliar na realização e na avaliação dos exames cardiológicos; e à profa. dra. Christina Maeda Takiya, pelo auxílio oferecido no Laboratório de Patologia Celular do Departamento de Histologia e Embriologia da Universidade Federal do Rio de Janeiro.

\section{CONFLITO DE INTERESSES}

Os autores declararam inexistência de conflito de interesses.

\section{REFERÊNCIAS BIBLIOGRÁFICAS}

1. Luepker RV, Apple FS, Christenson RH, Crow RS, Fortmann SP, Goff D, et al. Case definitions for acute coronary heart disease in epidemiology and clinical research studies: a statement from the AHA Council on Epidemiology and Prevention; AHA Statistics Committee; World Heart Federation Council on Epidemiology and Prevention; the European Society of Cardiology Working Group on Epidemiology and Prevention; Centers for Disease Control and Prevention; and the National Heart, Lung, and Blood Institute. Circulation. 2003;108(20):2543-9.

2. Pontes RMN, Leães PE. Remodelamento ventricular: dos mecanismos moleculares e celulares ao tratamento. Rev Soc Cardiol Rio Grande do Sul. 2004;13(3):1-7.

3. Orlic D. The strength of plasticity: stem cell for cardiac repair. Int J Cardiol. 2004;95 Suppl 1:S16-9.

4. Hunt SA. Current status of cardiac transplantation. JAMA. 1988;280(19):1692-8.

5. Oh H, Bradfute SB, Gallardo TD, Nakamura T, Gaussin V, Mishina $Y$, et al. Cardiac progenitor cells from adult myocardium: homing, differentiation, and fusion after infarction. Proc Natl Acad Sci USA. 2003;100(21):12313-8.

6. Murrry CE, Wiseman RW, Schwartz SM, Hauschka SD. Skeletal myoblast transplantation for repair of myocardial necrosis. J Clin Invest. 1996;98(11):2512-23.

7. Reinecke H, Murry CE. Cell grafting for cardiac repair. Methods Mol Biol. 2003;219:97-112.

8. Zhou HP, Yi DH, Yu SQ, Sun GC, Cui Q, Zhu HL, et al. Administration of donor-derived mesenchymal stem cells can prolong the survival of rat cardiac allograft. Transplant Proc. 2006;38(9):3046-51.

9. Ohnishi S, Yanagawa B, Tanaka K, Miyahara Y, Obata H, Kataoka $M$, et al. Transplantation of mesenchymal stem cells attenuates myocardial injury and dysfunction in a rat model of acute myocarditis. J Mol Cell Cardiol. 2007;42(1):88-97.

10. Giordano A, Galderisi U, Mariano IR. From the laboratory bench to the patient's bedside: an update on clinical trials with mesenchymal stem cells. J Cell Physiol. 2007;211(1):27-35.

11. Poulsom R, Alison MR, Forbes SJ, Wright NA. Adult stem cell plasticity. J Pathol. 2002;197(4):441-56.

12. Wollert KC, Meyer GP, Lotz J, Ringes-Lichtenberg S, Lippolt $\mathrm{P}$, Breidenbach C. Intracoronary autologous bone-marrow cell transfer after myocardial infarction: the BOOST randomised controlled clinical trial. Lancet. 2004;364(9429):141-8.

13. Strauer BE, Kornowski R. Stem cell therapy in perspective. Circulation. 2003;107(7):929-34.

14. Murad-Netto S, Moura R, Romeo LJM, Manoel Neto A, Duarte N, Barreto F. Terapia de células-tronco no infarto agudo do miocárdio através de perfusão coronariana retrógrada. Uma nova técnica. Arq Bras Cardiol. 2004;83(4):349-51.

15. Suzuki K, Brand NJ, Smolenski RT, Jayakumar J, Murtuza B, Yacoub MH. Development of a novel method for cell transplantation through the coronary artery. Circulation. 2000;102(19 Suppl 3):III359-64.

16. Strauer BE, Brehm M, Zeus T, Köstering M, Hernadez A, Sorg $R V$, et al. Repair of infarcted myocardium by autologous intracoronary mononuclear bone marrow cell transplantation in humans. Circulation. 2002;106(15):1913-8.

17. Rangappa S, Entwistle JW, Wechsler AS, Kresh JY. Cardiomyocyte-mediated contact programs human mesenchymal stem cells to express cardiogenic phenotype. J Thorac Cardiovasc Surg. 2003;126(1):124-32.

18. Suzuki K, Murtuza B, Fukushima S, Smolenski RT, VarelaCarver A, Coppen SR, et al Targeted cell delivery into infarcted rat hearts by retrograde intracoronary infusion: distribution, dynamics, and influence in cardiac function. Circulation. 2004;110(11 Suppl 1):II-225-30.

19. Yokoyama S, Fukuda N, Li Y, Hagikura K, Takayama T, Kunimoto $\mathrm{S}$, et al. A strategy of retrograde injection of bone marrow mononuclear cells into the myocardium for the treatment of ischemic heart disease. J Mol Cell Cardiol. 2006;40(1):24-34.

20. Kornowski R, Fuchs S, Leon MB, Epstein SE. Delivery strategies to achieve therapeutic myocardial angiogenesis. Circulation. 2000;101(4):454-8.

21. Perin EC, Dohmann HF, Borojevic R, Silva SA, Sousa AL, Mesquita CT, et al. Transendocardial, autologous bone marrow cell transplantation for severe, chronic ischemic heart failure. Circulation. 2003;107(18):2294-302.

22. Fuchs S, Satler LF, Kornowski R, Okubagzi P, Weisz G, Baffour R, et al. Catheter-based autologous bone marrow myocardial injection in no-option patients with advanced coronary artery disease: a feasibility study. J Am Coll Cardiol. 2003;41(10):1721-4.

23. Christopherson KW $2^{\text {nd }}$, Hangoc G, Mantel CR, Broxmeyer HE. Modulation of hematopoietic stem cell homing and engraftment by CD26. Science. 2004;305(5686):1000-3.

24. Vulliet PR, Greeley M, Halloran SM, MacDonald KA, Kittleson MD. Intra-coronary arterial injection of mesenchymal stromal cells and microinfarction in dogs. Lancet. 2004; 363(9411):783-4.

25. Hou D, Youssef EA, Brinton TJ, Zhang P, Rogers P, Price ET, et al. Radiolabeled cell distribution after intramyocardial, intracoronary, and interstitial retrograde coronary venous delivery: implications for current clinical trials. Circulation. 2005;112(9 Suppl):I-150-6. 